\title{
Path Analysis on the Biopsychosocial Factors Affecting the Quality of Life in Patients with Breast Cancer
}

\author{
Rizka Amalia Dewi'), Ambar Mudigdo²), Eti Poncorini Pamungkasari3) \\ 1)Masters Program in Public Health, Universitas Sebelas Maret \\ 2)Department of Pathology Anatomy, Faculty of Medicine, Universitas Sebelas Maret \\ 3)Faculty of Medicine, Universitas Sebelas Maret
}

Background: Breast cancer is the most common cancer among women, affecting 2.1 million women every year. Assessment of quality of life is considered the most important and strong indicator for breast cancer outcomes. The purpose of this study was to analyze biopsychosocial factors that affect the quality of life of breast cancer patients.

Subjects and Method: A cross-sectional study was conducted in the breast cancer community in Surakarta, Central Java from December 2019 to January 2020. A sample of 200 breast cancer patients was selected by simple random sampling. The dependent variable was the quality of life of breast cancer patients. The independent variables were stadium, chemotherapy, length of diagnosis, age, depression, coping strategies, social networks, level of knowledge, education level, income level, employment status, and marital status. Quality of life was measured by WHO-QOL-BREF. Other data were collected by questionnaire. Data were analyzed by path analysis using the Stata 13 application.

Results: The quality of life of breast cancer patients was directly increased by high family income $(b=3.27 ; 95 \% \mathrm{CI}=1.67$ to $4.87 ; \mathrm{p}<0.001)$, strong social network $(\mathrm{b}=2.61 ; 95 \% \mathrm{CI}=0.96$ to 4.26; $\mathrm{p}=0.002$ ), length of diagnosis $\geq 24$ months $(b=2.68 ; 95 \% C I=0.98$ to $4.39 ; p=0.002)$, good coping strategy $(b=1.65 ; 95 \% \mathrm{CI}=0.12$ to 3.19 ; $\mathrm{p}=0.034)$, and finished chemotherapy $(\mathrm{b}=1.32$; $95 \% \mathrm{CI}=-0.22$ to $2.87 ; \mathrm{p}=0.093)$. The quality of life of breast cancer patients was directly decreased by depression ( $b=-2.78 ; 95 \% \mathrm{CI}=-4.41$ to $1.15 ; \mathrm{p}=0.001)$ and advanced stage $(\mathrm{b}=-2.43$; $95 \% \mathrm{CI}=-4.04$ to $0.83 ; \mathrm{p}=0.003)$. Quality of life was indirectly affected by coping strategy, marital status, chemotherapy, knowledge, length of diagnosis, age, employment, and education.

Conclusion: The quality of life of breast cancer patients is directly increased by high family income, strong social network, length of diagnosis $\geq 24$ months, good coping strategy, and finished chemotherapy. The quality of life of breast cancer patients is directly decreased by depression and advanced stage. Quality of life is indirectly affected by coping strategy, marital status, chemotherapy, knowledge, length of diagnosis, age, employment, and education.

Keywords: quality of life, breast cancer, path analysis

\section{Correspondence:}

Rizka Amalia Dewi. Masters Program in Public Health, Universitas Sebelas Maret. Jl. Ir. Sutami 36A, Surakarta 57126, Central Java, Indonesia. Email: drizkaez@gmail.com. Mobile: +6282313121768.

Cite this as:

Dewi RA, Mudigdo A, Pamungkasari EP (2020). Path Analysis on the Biopsychosocial Factors Affecting the Quality of Life in Patients with Breast Cancer. J Epidemiol Public Health. 05(01): 119-131. https://doi.org/10.26911/jepublichealth.2020.05.01.12.

cc) (i) (2) Journal of Epidemiology and Public Healthis licensed under a Creative Commons Attribution-NonCommercial-ShareAlike 4.0 International License.

\section{BACKGROUND}

Breast cancer is the most common cancer among women, affecting 2.1 million women every year and the biggest cause of cancer- related death among women. In 2018, an estimated 627,000 women died of breast cancer, which is about $15 \%$ of all cancer deaths among women. Breast cancer is a type 
Dewi et al./ Biopsychosocial factors affecting the quality of life in patients with breast cancer

of cancer with the highest percentage of cases that is equal to $42.1 \%$ after that is cervical cancer (23.4\%), lung cancer (12.4\%), colon cancer (12.1\%), ovarian cancer (9.7\%). Breast cancer is the highest cause of death among other cancers which is $17.0 \%$, after that there is cervical cancer (13.9\%), lung cancer (10.9\%), liver cancer (7.5\%), and colon cancer (6.9\%) (WHO, 2018).

Basic Health Research Data (RISKESDAS) in 2018, found the prevalence of sufferers in 2018, obtained the prevalence of cancer patients in the population of all ages in Indonesia by $1.79 \%$ increased compared with the prevalence of cancer patients in 2013 which was $1.4 \%$. The highest cancer prevalence in 2018 is in the Province of Yogyakarta, which is $4.86 \%$, far higher than the national rate (1.8\%). The next highest prevalence was in West Sumatra Province (2.47\%), Gorontalo (2.44\%), DKI Jakarta (2.33\%), Bali (2.27\%), Central Sulawesi (2.23\%), East Java (2.17\%), North Kalimantan (2.16\%) \%), South Kalimantan (2.13\%), and Central Java (2.11\%). Central Java Province is included in the top 10 highest prevalence of breast cancer in Indonesia.

Breast cancer patients in the first year after diagnosis will experience depression. Patients will experience psychological disorders such as anxiety disorders, anger, low self-esteem, and low emotional support (Rios and Pedaza, 2018).

The population of women who have survived breast cancer over the past 5 years is increasing and growing. Care and rehabilitation are increasingly important to support the recovery of breast cancer patients. The quality of life for breast cancer patients in the long term will improve after chemotherapy and or radiotherapy treatment compared with patients who have not or who are currently undergoing of chemotherapy (Schmidt, 2018). The socioeconomic situation in general is related to various health problems.
A good social economy will affect someone's awareness, willingness and ability to improve their health (Lusiatun, 2016).

Unmarried breast cancer patients are associated with poor quality of life and support the idea that strong family relationships, close communication with partners, have a significant effect on improving the quality of life of breast cancer patients (Farha et al., 2017). Social networking is a process of observing social structures in socializing that are interconnected between them. Breast cancer patients who have a weak social network will reduce the quality of life of these patients (Graells-Sans,2018).

Lovely Pink Solo is a breast cancer community in Surakarta. The goal of the Lovely Pink Solo community is as a forum to exchange information about breast cancer, share experiences about medicine, provide mutual support, think positively and strengthen breast cancer patients so that their confidence returns. From the background described, the researchers will conduct a study to analyze various biopsychosocial and economic factors that affect the quality of life of breast cancer patients in Surakarta.

\section{SUBJECTS AND METHOD}

\section{Study Design}

This was an analytic observational study with a cross sectional design. The study was conducted at the Lovely Pink Solo breast cancer community, in Surakarta, Central Java, from December 2019 to January 2020.

\section{Population dan Sample}

The population in this study consisted of breast cancer patients in the Lovely Pink Solo community. A sample of 200 patients was selected by simple random sampling.

\section{Study Variables}

The dependent variable was the quality of life. The independent variables were cancer stage, chemotherapy, duration of diagnosis, age, depression, coping strategies, social net- 
Dewi et al./ Biopsychosocial factors affecting the quality of life in patients with breast cancer

works, level of knowledge, level of education, level of income, and employment status.

\section{Operational Definition of Variables} Quality of life is an assessment of study subjects about her well-being which includes physical, psychological, social, and environmental health resulting from breast cancer. The instruments used are WHOQOL-BREF. The measurement scale was continous, but it was transformed into dichotomous, coded $\mathrm{o}=$ poor and $1=$ good.

Cancer stage is the stage of cancer development based on the spread of cancer in the body when diagnosed. Data were collected using a questionnaire. The measurement scale was continous, but it was transformed into dichotomous.

Chemotherapy was a cancer treatment with various risks. Data is collected by using a questionnaire. The measurement scale was categorical, $\mathrm{O}=$ have not conduct chemotherapy or during chemotherapy and $1=$ after chemotherapy.

Marital status was a marriage bond that has been ratified by the KUA (Office of Religious Affairs). Data is collected using a questionnaire. The measurement scale was categorical, code $\mathrm{O}=$ not $\mathrm{married} /$ divorced and $1=$ married.

Social network was a study subject statement about how often the subject interacts with family, relatives and the community. Data was collected by questionnaire. The measurement scale was continous, but it was transformed into dichotomous, code $\mathrm{O}=$ weak and $1=$ strong.

Length of diagnosis is the time from the study subject diagnosed with breast cancer to date within months. Data were collected by questionnaire. The measurement scale was continous, but it was transformed into dichotomous, code $0<24$ months and $1=\geq 24$ months.

Age was the age of the subject at the time of the study in years. Data were collected using a questionnaire. The measurement scale was continous, but it was transformed into dichotomous, coded $\mathrm{o}=<45$ years old and $1=\geq 45$ years old.

Coping strategy was an expression of the subject on the thoughts and attitudes carried out in dealing with breast cancer they experience. The instruments used are BREFCOPE. The measurement scale was continous, but it was transformed into dichotomous, coded $0=$ weak and $1=$ strong .

Depression was a condition that makes a mood become prolonged disturbed and arises due to loss of hope or feelings of helplessness. Data were collected using the DASS questionnaire. The measurement scale was continous, but it was transformed into dichotomous, code $\mathrm{O}=$ not depressed and $1=$ depressed.

Level of knowledge was a statement from the subject of study on knowledge about breast cancer. Data were collected using a questionnaire. The measurement scale was continous, but it was transformed into dichotomous, coded $\mathrm{o}=$ low and $1=$ high.

Level of education was the last formal education taken by subjects and have a certificate. Data were collected using a questionnaire. The measurement scale was categorical, coded $0=<$ Senior high school and $1=$ $\geq$ Senior high school.

Family income was the average monthly family income each month in the last 6 months. Data was collected by using questionnaire. The measurement scale was continous, but it was transformed into dichotomous, code $\mathrm{o}=<5.6$ million and $1=\geq 5.6$ million.

Employment status is a statement of subjects about the status of employment at the time of study. Data were collected using a questionnaire. The measurement scale was categorical, coded $\mathrm{o}=$ not working or working at the house and $1=$ working outside the home. 
Dewi et al./ Biopsychosocial factors affecting the quality of life in patients with breast cancer

\section{Data Analysis}

\section{a. Univariate Analysis}

Univariate analysis was performed on each study variable. Categorical data were described in the frequency distribution table. Characteristics of continuous data samples were described in the $\mathrm{n}$ parameters, mean, $\mathrm{SD}$, minimum and maximum.

\section{b. Bivariate Analysis}

Bivariate analysis in this study used the Pearson product moment test. This test is to find out the relationship between $\mathrm{X}$ and $\mathrm{Y}$ variables.

\section{c. Multivariate Analysis}

Multivariate analysis is to determine the effect of various variables studied using Path Analysis by using the Stata 13 application.

\section{Research Ethics}

This study was conducted based on study ethics, namely informed consent, anonymity, confidentiality, and ethical study. The study ethics was obtained from the Health Research Ethics Committee at Dr. Moewardi Hospital, Surakarta, Indonesia, No. 1.335 /XII/HREC/2019.

\section{RESULTS}

\section{Sample Characteristics}

Table 1 shows sample characteristics (continous data). Categorical data are explained in Table 2. Table 2 shows the age of the sample is mostly $\geq 40$ years old (92.5\%), working at hoe (49\%), and had education $\geq$ Ssenior high school (80\%).

Table 1. Sample Characteristics (continuous data)

\begin{tabular}{lccccc}
\hline \multicolumn{1}{c}{ Variable } & n & Mean & SD & Min. & Max. \\
\hline Quality of life & 200 & 304.03 & 49.65 & 211 & 381 \\
Coping strategy & 200 & 50 & 3.82 & 39 & 56 \\
Knowledge & 200 & 8.91 & 1.43 & 5 & 12 \\
Depression & 200 & 2.39 & 1.49 & 1 & 9 \\
Social network & 200 & 14.10 & 1.50 & 9 & 16 \\
\hline
\end{tabular}

Table 2. Sample characteristics (categorical data)

\begin{tabular}{|c|c|c|c|}
\hline Characteristics & Category & $\mathbf{n}$ & \% \\
\hline \multirow[t]{2}{*}{ Age } & $<40$ years old & 15 & 7.5 \\
\hline & $\geq 40$ years old & 185 & 92.5 \\
\hline \multirow[t]{2}{*}{ Education } & $<$ Senior high school & 40 & 20 \\
\hline & $\geq$ Senior high school & 160 & 80 \\
\hline \multirow[t]{6}{*}{ Employment } & Not working/Working at home & 98 & 49 \\
\hline & Farmers & 1 & 0.5 \\
\hline & Entrepreneur & 9 & 4.5 \\
\hline & General Employee & 35 & 17.5 \\
\hline & Civil Servant & 38 & 19 \\
\hline & And others & 19 & 9.5 \\
\hline \multirow[t]{2}{*}{ Income } & Low & 91 & 45.5 \\
\hline & High & 109 & 54.5 \\
\hline \multirow[t]{3}{*}{ Marital status } & Not married & 9 & 4.5 \\
\hline & Widowed/divorced & 73 & 36.5 \\
\hline & Married & 118 & 59 \\
\hline \multirow[t]{2}{*}{ Length of diagnosis } & $<24$ months & 115 & $57 \cdot 5$ \\
\hline & $\geq 24$ months & 85 & 42.5 \\
\hline \multirow[t]{2}{*}{ Stage } & Early & 119 & 59.5 \\
\hline & Advanced & 81 & 40.5 \\
\hline \multirow[t]{3}{*}{ Chemotherapy } & Have not/1-3 times & 6 & 3 \\
\hline & $>3$ times & 46 & 23 \\
\hline & Finished chemotherapy & 148 & 74 \\
\hline
\end{tabular}


Dewi et al./ Biopsychosocial factors affecting the quality of life in patients with breast cancer

Maternal level of education which is above HS is 160 people (80\%). Mothers who mostly work in the home are 98 people (49\%). High level of family income was $54.5 \%$. Most of the subjects are married by 118 people (59\%). The length of diagnosis of subjects was less than 24 months (57.5\%). The initial stage of the sample is 119 people (59.5\%). Most of the samples had finished doing chemotherapy (74\%).

\section{The result of bivariate analysis}

Table 3 shows that the results of a bivariate analysis on biopsychosocial and economic factors that affect the quality of life of breast cancer patients.

Table 3 shows that family income $(\mathrm{r}=$ $0.61 ; \mathrm{p}<0.001)$, length of diagnosis $(\mathrm{r}=0.46$; $\mathrm{p}<0.001)$, coping strategies $(\mathrm{r}=0.52 ; \mathrm{p}$ $<0.001)$, knowledge $(\mathrm{r}=0.34 ; \mathrm{p}<0.001)$, and social networks $(\mathrm{r}=0.55 ; \mathrm{p}<0.001)$ improve the quality of life of breast cancer patients. Table 3 shows that depression decreases the quality of life of breast cancer patients $(\mathrm{r}=$ $0.65 ; \mathrm{p}<0.001)$.

Table 3. Bivariate correlations between income, duration of diagnosis, coping strategies, knowledge, depression, social networks, and the quality of life of breast cancer patients

\begin{tabular}{lcc}
\hline \multicolumn{1}{c}{ Independent Variables } & $\mathbf{r}$ & $\mathbf{p}$ \\
\hline Income & 0.61 & $<0.001$ \\
Length of diagnosis & 0.46 & $<0.001$ \\
Coping strategy & 0.52 & $<0.001$ \\
Knowledge & 0.34 & $<0.001$ \\
Depression & -0.65 & $<0.001$ \\
Social networking & 0.55 & $<0.001$ \\
\hline
\end{tabular}

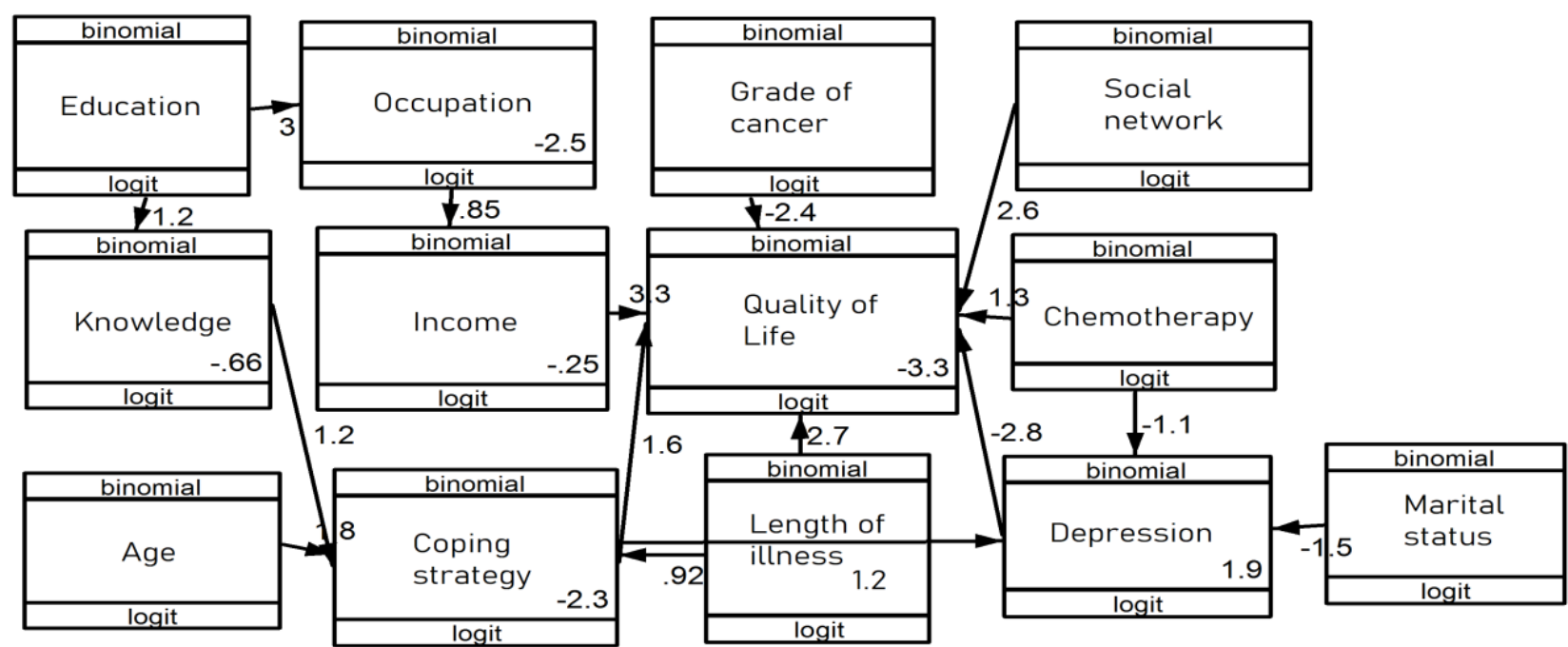

Figure 1. Structural Model of Path Analysis

\section{Path analysis}

Figure 1 depicted structural model of path analysis. Table 4 showed psychosocial and economic factors that affect the quality of life of breast cancer patients. Table 4 showed that there was a direct effect on family income, depression, social networks, duration of diagnosis, stage, coping strategies and chemotherapy from the quality of life of breast cancer patients.

Table 4 showed that the quality of life of breast cancer patients is directly affected by 
Dewi et al./ Biopsychosocial factors affecting the quality of life in patients with breast cancer

high family income $\geq 5.6$ million $(b=3.27$; $95 \% \mathrm{CI}=1.67$ to $4.87 ; \mathrm{p}<0.001)$, strong social network $(\mathrm{b}=2.61 ; 95 \% \mathrm{CI}=0.96$ to 4.26 ; $\mathrm{p}=$ o.002), length of diagnosis $\geq 24$ months $(b=$ 2.68; $95 \% \mathrm{CI}=0.98$ to $4.39 ; \mathrm{p}=0.002)$, strong coping strategy $(\mathrm{b}=1.65 ; 95 \% \mathrm{CI}=0.12$ to $3.19 ; \mathrm{p}=0.034)$, and finished chemotherapy $(\mathrm{b}=1.32 ; 95 \% \mathrm{CI}=-0.22$ to $2.87 ; \mathrm{p}=$ 0.093).

Table 4. Psychosocial and economic factors that affect the quality of life of breast cancer patients

\begin{tabular}{|c|c|c|c|c|c|}
\hline \multirow{2}{*}{$\begin{array}{l}\text { Dependent } \\
\text { Variable }\end{array}$} & \multirow{2}{*}{ Independent Variable } & \multirow{2}{*}{$\begin{array}{c}\text { Path } \\
\text { Coef. } \\
\text { (b) }\end{array}$} & \multicolumn{2}{|c|}{$95 \% \mathrm{CI}$} & \multirow[b]{2}{*}{$\mathbf{p}$} \\
\hline & & & $\begin{array}{l}\text { Lower } \\
\text { Limit }\end{array}$ & $\begin{array}{l}\text { Upper } \\
\text { Limit }\end{array}$ & \\
\hline \multicolumn{6}{|l|}{ Direct effect } \\
\hline \multirow{7}{*}{$\begin{array}{l}\text { Quality of life } \\
\text { (good) }\end{array}$} & $\leftarrow$ Income $(\geq$ Rp.5.6 million $)$ & 3.27 & 1.67 & 4.87 & $<0.001$ \\
\hline & $\leftarrow$ Depression & -2.78 & -4.41 & -1.15 & 0.001 \\
\hline & $\leftarrow$ Social network (strong) & 2.61 & 0.96 & 4.26 & 0.002 \\
\hline & $\leftarrow$ Length of diagnosis $(\geq 24$ months $)$ & 2.68 & 0.98 & 4.39 & 0.002 \\
\hline & $\leftarrow$ Stage (advanced) & -2.43 & -4.04 & -0.83 & 0.003 \\
\hline & $\leftarrow$ Coping strategy(good) & 1.65 & 0.12 & 3.19 & 0.034 \\
\hline & $\leftarrow$ Chemotherapy (finished) & 1.32 & -0.22 & 2.87 & 0.093 \\
\hline \multicolumn{6}{|c|}{ Indirect effect } \\
\hline \multirow[t]{3}{*}{ Depression } & $\leftarrow$ Coping strategy(good) & -1.25 & -1.92 & -0.58 & $<0.001$ \\
\hline & $\leftarrow$ Married & -1.54 & 2.21 & -0.87 & $<0.001$ \\
\hline & $\leftarrow$ Chemotherapy (finished) & -1.13 & -1.81 & -0.32 & 0.005 \\
\hline Coping & $\leftarrow$ Knowledge (good) & 1.18 & 0.56 & 1.89 & $<0.001$ \\
\hline \multirow[t]{2}{*}{ strategy (good) } & $\leftarrow$ Length of diagnosis ( $\geq 24$ months $)$ & 0.92 & 0.28 & 1.56 & 0.005 \\
\hline & $\leftarrow$ Age $(\geq 40$ years old $)$ & 1.79 & 0.43 & 3.15 & 0.010 \\
\hline $\begin{array}{l}\text { Income } \\
\text { ( } \geq \text { Rp. } 5.6 \text { million }\end{array}$ & $\underset{\text { a) }}{\leftarrow}$ Employment (outside the home) & 0.85 & 0.28 & 1.42 & 0.003 \\
\hline $\begin{array}{l}\text { Employment } \\
\text { (outside the home }\end{array}$ & $\underset{\mathrm{e})}{\leftarrow}$ Education ( $\geq$ Senior high school) & 3.03 & 1.82 & 4.26 & $<0.001$ \\
\hline $\begin{array}{l}\text { Knowledge } \\
\text { (good) }\end{array}$ & $\leftarrow$ Education ( $\geq$ Senior high school) & 1.21 & 0.49 & 1.93 & 0.001 \\
\hline \multicolumn{6}{|c|}{ n observation $=200$} \\
\hline \multicolumn{6}{|l|}{$\mathrm{AIC}=1301.21$} \\
\hline $\mathrm{BIC}=1373.77$ & & & & & \\
\hline
\end{tabular}

\section{DISCUSSION}

1. The effect of income on the quality of life

The results of this study showed that breast cancer patients with family income $\geq 5.6$ million have the possibility to have a good quality of life by 3.27 times than family income $<5.6$ million ( $b=3.27$; CI 95\%= -1.67 to 4.87 ; $\mathrm{p}<0.001)$.
Table 4 shows that depression directly reduced the quality of life of breast cancer patients $(b=-2.78 ; 95 \% \mathrm{CI}=-4.41$ to -1.15 ; $\mathrm{p}<0.001)$. Figure 1 shows that the quality of life of breast cancer patients is indirectly affected by coping strategies, marital status, chemotherapy, knowledge, length of diagnosis, age, employment and education.

The results of this study were in line with Alshreef et al. (2019) which stated that income has a significant influence on the quality of life of breast cancer patients.

Cancer treatment costs are related to the burden of quality of life for breast cancer patients. The financial pressure is related to the medical care costs of breast cancer patients. In addition, financial tension also influences bad emotional changes for breast 
Dewi et al./ Biopsychosocial factors affecting the quality of life in patients with breast cancer

cancer patients (Perry et al., 2019). Emotional changes in breast cancer patients on low incomes would lead to stress and can cause depression (Patel et al., 2018).

\section{The effect of depression on quality of life}

This study showed that breast cancer patients with depression would reduce the quality of life than non-depressed $(b=-2.78 ; 95 \% \mathrm{CI}=$ 4.41 to -1.15; $\mathrm{p}<0.001)$. This study was in line with Kugbey et al. (2019), which stated that breast cancer patients with high depression would reduce quality of life. This explained that breast cancer patients with low depression would improve the quality of life of breast cancer patients.

Depression is the number one factor that affect the functional status of breast cancer patients. The presence of depressive symptoms in people with breast cancer negatively affected their well-being, social role, emotional status, and decreased their quality of life (Calderon et al., 2019). If depression in breast cancer patients is not managed properly, then it might be an obstacle for breast cancer patients to return to their previous state (Muhit and Siyoto, 2016). The depression experienced by breast cancer patients changes with time. After that breast cancer patients will recover from depression and can continue to live for further medical treatment in order to improve their quality of life (Kim et al., 2018).

\section{The effect of soxial network on qua- lity of life}

The results showed that there was a relationship between social networks and quality of life. Breast cancer patients with strong social networks were 2.61 times more likely to have a good quality of life than weak social networks ( $\mathrm{b}=2.61 ; 95 \% \mathrm{CI}=0.96$ to $4.26 ; \mathrm{p}=$ 0.002). This study explained that breast cancer patients with strong social networks would improve the quality of life of breast cancer patients. In addition, a strong social network would foster various social support among members of breast cancer patients.

Social networks can encourage breast cancer patient participation in healthy behavior and health care. Social networks can also provide various types of social support (Gunn et al., 2017). Other study also supported that strong social networks are shown to have better breast cancer survival and are associated with lower mortality. Breast cancer patients who have strong social networks tend to have greater physical activity and a lower prevalence of smoking, obesity and alcohol consumption (Kroenke, 2018).

The results showed that there was a relationship between the length of diagnosis and quality of life. Breast cancer patients with a diagnosis duration of $\geq 24$ months had the possibility for good quality of life by 2.68 times greater than the length of diagnosis $<24$ months $(\mathrm{b}=2.68 ; 95 \% \mathrm{CI}=0.98$ to 4.39; $\mathrm{p}=0.002)$. The duration of diagonosis can be related to depression in breast cancer patients. Early breast cancer patients were diagnosed with breast cancer as having a worse quality of life than breast cancer patients after two years of diagnosis.

The diagnosis of breast cancer can create psychological problems for survivors, family and relatives. In addition, the acceptance phase of getting cancer is different for everyone. Starting from the diagnosis, the treatment phase and the initial recovery period (Michaelides and Constantinou, 2020) 4. The effect of stage on quality of life The results showed that there was a relationship between stage and quality of life. Patients with advanced stage breast cancer have the possibility to reduce their quality of life by 2.43 times greater compared to the initial/early stage $(b=-2.43 ; 95 \% \mathrm{CI}=-4.04$ to $0.83 ; \mathrm{p}=0.003)$. This study was in line with Jeffe et al. (2015), which stated that earlystage cancer has a relatively high quality of life and improved compared to advanced 
Dewi et al./ Biopsychosocial factors affecting the quality of life in patients with breast cancer

stage. This is mainly due to early detection with increased breast cancer screening and improved cancer treatments that are already very good. However, it still need regular maintenance to avoid recurrence.

The introduction of breast cancer is important to reduce new cases. Prevention and early detection would become easier when risk factors and cancer symptoms are identified. Cancer cases found at an early stage have received fast and appropriate treatment and would provide a longer life expectancy. So it is important to conduct checks regularly in efforts to prevent and detect cancer early (Ministry of Health Republic of Indonesia, 2016).

\section{The effect of coping strategy on qua- lity of life}

The results showed that there was a relationship between coping strategies and quality of life. Breast cancer patients with good coping strategies have the possibility for a good quality of life by 1.65 times greater than the poor coping strategies $(b=1.65 ; 95 \% \mathrm{CI}=0.12$ to $3.19 ; \mathrm{p}=0.034$ ).

Coping strategies are cognitive attempts and intentional behaviors to manage or reduce emotionally threatening situations and stress in life. The strategies used in coping include accepting situations and playing an active role, eliminating stressors or moving away from stressors, releasing feelings connected to stressors and see stressors as something positive on growth (Blum et al., 2012).

Patients with breast cancer faces a fear of death and the financial burden of care. There is also loss of self confidence, insecurity, instability and sadness when people make unconscious and deliberate comments to the women with breast cancer. Such cases require coping strategies (Iddrisu et al., 2019).

Various coping strategies are carried out by listening to music and engaging in various hobbies, attention and mediation can be effective in reducing pressure and increasing welfare among women with breast cancer. Positive thinking, willingness to fight disease and having hope are reported as important coping strategies among women with breast cancer (Drageset et al., 2016).

\section{The effect of chemotherapy on qua- lity of life}

The results showed that there was a relationship between chemotherapy and quality of life. Breast cancer patients with chemotherapy treatments that have been completed have the possibility to improve the quality of life by 1.32 times greater than those who still conduct the chemotherapy $(\mathrm{b}=1.32 ; 95 \% \mathrm{CI}=$ -0.22 to 2.87; $\mathrm{p}=0.093$ ). The results showed that quality of life improved in one year after chemotherapy treatment was given (Kwiatkowski et al., 2013).

Long-term breast cancer patients according to longitudinal studies stated that older breast cancer patients can maintain good emotional and cognitive function. This study showed that personality and social resources influenced the long term emotional welfare of breast cancer sufferers (Durá-Ferrandis et al., 2017).

Other study stated that after chemotherapy, participating in a routine exercise program such as sports or yoga for breast cancer can maintain physical exercise and have long-term effects both for the individual and social benefits (Mijwel et al., 2019).

7. Indirect effect on the quality of life a. The effects of coping strategies on depression

The results of this study indicated that there was an indirect effect of a good coping strategy on the quality of life of breast cancer patients through depression. This was in accordance with Geyikci et al. (2018), which found that there was a negative relationship between depression and coping strategies in breast cancer women. Breast cancer patients 
Dewi et al./ Biopsychosocial factors affecting the quality of life in patients with breast cancer

can face depression with good coping strategies.

\section{b. The effects of marriage on depres- sion}

The results showed that there was an indirect effect of marital status on the quality of life of breast cancer patients through depression. Married breast cancer patients showed that in the first 5 years of diagnosis of breast cancer, married women have significantly higher optimism than unmarried women. This is because women who have a partner have a good quality of life so that it would be easier to deal with depression which would produce a good coping strategy for further medical treatment (Croft et al., 2014).

Being single or not having a partner is associated with a higher level of depression compared to being married (Wittenberg, 2010). The results showed that partner support in dealing with breast cancer was the most important source of support compared to other social supports (Salakari et al., 2017).

\section{c. The effects of chemotherapy on dep- ression}

The results showed that there was an indirect effect of finished chemotherapy on the quality of life of breast cancer patients through depression. Breast cancer patients who have not or are currently undergoing chemotherapy treatment would experience symptoms of depression related to pain and chemotherapy side effects. This would reduce their welfare, social role, emotional status, and decrease their quality of life. Untreated depression interferes with personal relationship, sexual and temporary rehabilitation can reduce patients' ability to cope with the disease and their quality of life (Calderon, 2019).

\section{d. The effects of knowledge on coping strategies}

The results showed that there was an indirect effect of the level of knowledge on the quality of life of breast cancer patients through cop- ing strategies. Cancer patients stated that knowledge and understanding of breast cancer would improve their quality of life.

Women's knowledge and understanding of breast cancer are a source of hope and empowerment for participants based on studies during the diagnosis and management of diagnosis care. The authors discussed the importance of breast screening and mammograms that have been recommended by governments in the United States. According to American women, their knowledge and understanding of breast cancer helps them to identify changes in their breasts and look for early paramedics. Coping strategies to overcome the effects of treatment by keeping their minds from their diseases and always having positive thoughts (Williams and Jeanetta, 2015).

\section{e. The effects of length of diagnosis on coping strategies}

The results showed that there was an indirect effect of the length of diagnosis on the quality of life of breast cancer patients through coping strategies.

Some of the copingstrategiesare social support and religious approaches (Kahana et al., 2016). The results of a qualitative study from Devi and Fong (2019) stated that breast cancer patients in Singapore after being diagnosed with breast cancer are getting closer to God, often going to church with the aim of praying for healing the disease, reading the scriptures, using artifacts to ask healing to god.

\section{f. The effects of age on coping strate- gies}

The results showed that there was an indirect effect of age $\geq 45$ years on the quality of life of breast cancer patients through coping strategies.

The result of this study was in line with You et al. (2017), which stated that there was an indirect effect between age and quality of life. Psychological adjustments to cancer 
Dewi et al./ Biopsychosocial factors affecting the quality of life in patients with breast cancer

occur in the process of development in dealing with cancer. Many age differences are observed in cancer and psychological experiences that underlie the process. Even though older adults may have cancer and more cancer than young women, but young women have worse emotional stress than older women when diagnosed with cancer. This is related to symptoms of depression and anxiety, quality of life after treatment and fertility. g. The effects of employment on coping income

The results showed that there was an indirect effect of working outside the home on the quality of life of breast cancer patients through income.

Work and quality of life are affected by financial problems. After being diagnosed with breast cancer, a breast cancer survivor would feel worried about her work because after being diagnosed with breast cancer, the patient would conduct medical treatment so that activity must also be limited so that it can cause a decrease in quality of life (Sleight, 2017). Breast cancer patients who were not working would have a financial burden on the family and would increase depression in patients (Sharp et al., 2015).

\section{h. The effects of education on employ- ment}

The results showed that there was an indirect effect of the level of education on the quality of life of breast cancer patients through employment, a low level of education of patients and not working or working at home would have a low effect of knowledge in seeking information. Lack of knowledge about disease management and their awareness in controlling risk factors that can cause disease to be worse and eventually lead to depression (Ogoncho et al., 2016).

\section{i. The effects ofeducation on coping knowledge}

The results showed that there was an indirect effect of the level of education on the quality of life of breast cancer patients through knowledge.

Education of a breast cancer patient can improve the quality of life of breast cancer patients. Patients with higher education have a greater chance of knowing their disease. While low education is a predictor of psychological comorbidity in breast cancer patients (Srivastava et al, 2016).

Higher education would affect someone's knowledge. Higher education would affect someone's mindset in overcoming problems, so that disease management can be done immediately from an early age (Nuryati, 2018).

\section{AUTHOR CONTRIBUTION}

Rizka Amalia Dewi collected the data, did data analysis, and wrote the manuscript. Ambar Mudigdo played a role in the formulation of the background. Eti Poncorini Pamungkasari assisted in formulating a framework for study and discussion

\section{CONFLICT OF INTEREST}

There was no conflict of interest in this study.

FUNDING AND SPONSORSHIP This study used personal funds.

\section{ACKNOWLEDGEMENT}

The authors would like to thank to the head of the Pink Lovely Solo community in Surakarta for allowing this study to be carried out. Thank you to all patients who have agreed to work together to become the respondents

\section{REFERENCE}

Alshreef A, Mac Quilkan K, Dawkins B, Riddin J, Ward S, Meads D,Taylor M,et al. (2019). Cost-effectiveness of docetaxel and paclitaxel for adjuvant treatment of early breast cancer: Adaptation of a model based economic evaluation from the united kingdom to South Africa. Values Health Reg Issues (19): 65-74. 
Dewi et al./ Biopsychosocial factors affecting the quality of life in patients with breast cancer

https://doi.org/10.1016/j.vhri.2019.o3.001.

Blum S, Brow M, Silver C (2012). Coping strategy. 596-601. https://doi.org/10.1016/b978-0-12-37500o-6.00110.

Calderon C, Carmona-Bayonas A, Hernandez R, IGhanem I, Castelo B, Castro EM, Ferreira E, et al. (2019). Effects of pessimism, depresssion, fatigue, and pain on functional health related quality of life in patients with resected non-advanced breast cancer. The Breast. (44). https://doi.org/10.1007/soo520-0142308-y.

Croft L, Sorki J, Gallicchio L (2014). Marital status and optimism score among breast cancer survivors. Support Care Cancer. https://doi.org/10.1007/soo520-014-2308-y.

Devi M, Fong KK (2019). Spiritual experiences of women with breast cancer in singapore: A qualitative study.Asia Pac J Oncol Nurs.6(2); 145. https://doi.org/10.4103/apjon.apjon_77_18.

Drageset S, Lindstrøm TC, Underlid K (2016).“I just have to move on": Women's strategi coping experiences and reflections following their first year after primary breast cancer surgery. Eur J Oncol Nurs.21: 205-211. http://doi.org/10.1016/j.ejon.2015.10.005.

Durá-Ferrandis E, Mandelblatt JS, Clapp J, Luta G, Faul LA, Kimmick G, Cohen HJ, et al. (2017). Personality, coping, and social support as predictors of longterm quality oflife trajectories in older breast cancer survivors: CALGB protocol 369901 (Alliance). Psychooncology 26(11): 1914-1921. http://doi.org/10.1002/pon.4404.

Farha NHA, Khatib MT, Salameh H, Zyoud SH (2017). Cancer-related post treatment pain and its impact on healthrelated quality of life in breast cancer patients: a cross sectional study in
Palestine. Asia Pac Fam Med (16):7. http://doi.org/10.1186/s12930-017-OO37-3

Geyikci R, Cakmak S, Demirkol ME, Uguz S (2018). Correlation of anxiety and depression levels with attitudes towards strategi coping with illness and socio demo graphic characteristics in patients with a diagnosis of breast cancer. $J$ Neuro Neurosurg Psychiatry, 31(3): 246-257. https://doi.org/10.5350/DAJPN2018310302.

Graells-Sans A, Serral G, Puigpinós-Rieraa R, DAMA GC (2018). Social inequalities in quality of life in a cohort of women diagnosed with breast cancer in Barcelona (DAMA cohort). Cancer Epidemiol (54): 38-47. https://doi.org/10.1016/j.canep.2018.03.007.

Gunn CM, Parker VA, Bak Sm, Ko N, Nelson KP, Battaglia TA (2017). Social network structures of breast cancer patients and the contributing role of patient navigators. The Oncologist, (22): 918-924. http://doi.org/10.1634/theoncologist.2016-0440.

Iddrisu M, Aziato L, Dedey F (2019) A qualitative study on coping strategies of young women living with breast cancer in Ghana. IJANS (11):100-173. https://doi.org/10.1016/j.ians.2019.100173.

Jeffe DB, Pe' rez M, Cole EF, Liu Y, Schootman $M$ (2015). The effects of surgery type and chemotherapy on early stage breast cancer patients' quality of life over 2-year follow-up. Ann Surg Oncol. https://doi.org/10.1245/s10434-015-4926-0.

Kahana E, Kahana B, Langendoerfer KB, Kahana $B$, Tran SA (2016). Elderly cancer survivors reflect on strategi coping strategies during the cancer journey. Gerontol Geriatr Med. 5: (5). https://doi.org/10.4172/21677182.1000-337. 
Dewi et al./ Biopsychosocial factors affecting the quality of life in patients with breast cancer

Kugbey N, Meyer-Weitz A, Asante KO (2019). Access to health information, health literacy and health-related quality of life among women living with breast cancer: Depression and anxiety as mediators. Patient Educ Couns (102):13571363. https://doi.org/10.1016/j.pec.2019.02.014.

Kim S, Kim S,Shin S, Park M, Yoon Jc, Yoon J, Kim J (2018) . Changes in depression status during the year after breast cancer surgery and impact on quality of life and functioning. Gen Hosp Psychiatry. 50: 33-37. http://doi.org/10.1016/j.genhosppsych.2017.09.009.

Kroenke CH (2018). A conceptual model of social networks and mechanisms of cancer mortality, and potential strategies to improve survival. TBM (8):629-642. https://doi.org/10.1093/tbm/ibxo61.

Kwiatkowski F, Mouret-Reynier MA, Duclos M, Leger-Enreille A, Bridon F , Hahn T, Praagh-Doreau IF, et al. (2013). Long term improved quality of life by a 2week group physical and educational intervention shortly after breast cancer chemotherapy completion. Results of the programme of accompanying women after breast cancer treatment completion in thermal resorts' (PACThe) randomised clinical trial of 251 patients. Eur J Cancer: 49(7):1530-1538. https://doi.org/10.1016/j.ejca.2012.12.021

Lusiatun, Mudigdo A, Murti B (2016). The effect of self-efficacy, family support, and socio-economic factors on the quality of life of patients with breast cancer at Dr Moewardi Hospital. J Epidemiol Public Healt 1 (3):193-205. https://doi.org/10.-26911/jepublichealth.2016. 01.03.05.

Michaelides A, Constantinou C (2020). Integration of longitudinal psychoeducation programs during the phases of diagnosis, management and survivorship of breast cancer patients: A narrative review. J Cancer Policy (23): 100-214. https://doi.org/10.1016/j.jcpo.2019.100214.

Mijwel S, Jervaeus A, Bolam KA, Norrbom J, Bergh J, Rundqvist H, Wengström Y (2017). High-intensity exercise during chemotherapy induces beneficial effects 12 months into breast cancer survivorship. J Cancer Surviv (13):244-256. Https://doi.org/10.1007/s11764-019-0o747-z.

Ministry of Health of Republic Indonesia (2016). Bulan Peduli Kanker Payudara (Month of breast cancer awareness). Jakarta: Infodatin. Retrieved from: https://pusdatin.kemkes.go.id/article/view/17013100001/bulan-peduli-kankerpayudara.html

Muhith A, Siyoto S (2016). Pendidikan keperawatan geronik (Geronik nursing education).Yogyakarta: Andi Offset.

Nuryati S, Mudigdo A, Murti B (2018). Path analysis on the influence of educational level, stages of cancer, social support, and strategi coping strategy toward the quality of life of breast cancer patients in Dr. Moewardi Hospital, Surakarta.J Epidemiol Public Healt. 2(3): 225-232. https://doi.org/10.26911/jepublichealth.2017.02.03.03

Ogoncho IM, Omuga BO, Wakasiaka S, Mulva M (2016). Quality of life among gynaecological cancer patients receiving palliative care in Kenya : A crosssectional study. Afr J of Midwifery and Women's Health. 10(1): 2016-2019. https://doi.org/10.12968/ajmw.2016.1 o.1.15.

Patel V, Burns JK, Dhingra, Tarver L, Kohrt BA, Lund C (2018). Income inequality and depression:Systematic review and meta-analysis of the association and 
Dewi et al./ Biopsychosocial factors affecting the quality of life in patients with breast cancer

sstrategi coping review of mechanisms. World Psychiarty. 17(1):76-78. https://doi.org/10.1002/wps.20492.

Perry LM, Hoerger M, Seibert K, Gerhart JI, O’Mahony S, Duberstein (2019). Financial strain and physical and emotional quality of life in breast cancer. J Pain Symptom Manag (58): 3. https://doi.org/10.1016/j.jpainsymman.2019.05.0 11.

Rios MCV, Pedraza RS (2018). Anxiety and depression disorders in relation to the quality of life of breast cancer patients with locally advanced or disseminated stage. rev colom bpsiquiat 47(4):211220. https://doi.org/10.1016/j.rcp.2017.04.003.

Salakari M, Pylkkeanen L, Sillanmeaki L, Nurminen R, Rautava P, Koskenvuo M, Suominen S (2017). Social support and breast cancer: A comparatory study of breast cancer survivors, women with mental depression, women with hypertension and healthy female controls. The Breast, 35: 85-90. http://doi.org/10.1016/j.breast.2017.06.017.

Schmidt ME, Wiskemann J, Steindorf K (2018). Quality of life, problems, and needs of disease-free breast cancer survivors 5 years after diagnosis.Qual Life Res.https://doi.org/10.1007/s11136-018-1866-8.

Sharp L, Timmons A (2015). Prediagnosis employment status and financial circumstance spredict cancer-related financial stress and strain among breast and prostate cancer survivors. Support
Care Cancer. https://doi.org/10.1007/so0520-015-2832-4.

Sleight AG (2017). Occupational engagement in low-income latina breast cancer survivors. Am J Occup Ther. https://doi.org/10.1054/ajot.2017.711004.

Srivastava V, Ansari MA, Kumar A, Shah AG, Meena K, Sevach P, Singh OP (2016). Study of anxiety and depression among breast cancer patients from North India Clin Psychiatry, 2(1): 1-7. https://doi.org/10.21767/24719854.100017.

Wittenberg L, Yutsis M, Taylor S, GIESE-Davis J, Bliss-Isberg C, Star P, Spiegel D (2010). Marital status predicts change in distress and well-being in women newly diagnosed with breast cancer and their peer counselors.Breast J, 16(5): 481-489. https://doi.org/10.1111/j.15244741.2010.00964.x.

Williams F, Jeanetta S (2015). Lived experiences of breast cancer survivors after diagnosis, treatment and beyond: qualitative study. Health Expect. 19:631642. https://doi.org/10.1111/hex.12372.

World Health Organization (2018). Breast cancer: early diagnosis and screening. Retrieved from: https://www.who.int/cancer/prevention/diagnosis-screening/breast cancer/en/.

You J, Wang C, Rodriguez L, Wang X, Lu Q (2017). Personality, coping strategies and emotional adjustment among Chinese cancer patients of different ages. Eur J Cancer Care. 12(7): 81. https://doi.org/10.1111/ecc.12781. 